\title{
APLIKASI PEMASARAN DIGITAL MELALUI RUMAH PENGUSAHA MALANG RAYA DALAM PENATALAKSANAAN BISNIS PADA UMKM
}

\author{
Alexius Endy Budianto \\ endybudianto@unikama.ac.id \\ Didik Iswahyudi \\ didik@unikama.ac.id \\ Eris Dianawati \\ erisdianawati@gmail.com
}

\section{UNIVERSITAS KANJURUHAN MALANG}

\begin{abstract}
ABSTRAK
Perkembangan UMKM atau Usaha Mikro, Kecil dan Menengah di Indonesia akan semakin berkembang seiring dengan pertumbuhan ekonomi yang semakin meningkat. Selanjutnya berdampak pada pelaku UMKM agar lebih kreatif serta inovatif dalam perencanaan strategis pemasaran yang efektif. Sebuah UMKM akan mendapat kesulitan untuk berkembang jika para pelaku usaha kecil ini tidak memahami bagaimana cara memasarkan suatu produknya dengan efektif.. Dalam kesempatan ini kami bertujuan memberikan solusi lewat Program Pengembangan Kewirausahaan (PPK) Universitas Kanjuruhan Malang yang menggandeng Rumah Pengusaha Malang Raya (RPMR), berupa strategi pemesaran digital yaitu e_pasar. Metode yang kami gunukan dalam kegiatan ini yaitu melakukan workshop dengan membentuk kelompok usaha kecil menengah sesuai jangkauan pasarnya. Investasi yang kami berikan adalah berupa aplikasi pemasaran digital. Hasil dari investasi menunjukan perubahan yang signifikan dalam pemasaran pada anggota Rumah Pengusaha Malang Raya.
\end{abstract}

Kata kunci: Aplikasi Pemasaran Digital, Mendukung UMKM, PPK Unikama.

\section{PENDAHULUAN}

Malang merupakan salah satu kota yang mendukung produk-produk UMKM yang tersebar luas di area Malang. Namun ada beberapa permasalahan yang perlu diperhatikan yaitu : 1) Produk Usaha Mikro Kecil dan Menengah (UMKM) di Kota Malang belum sepenuhnya memahami pemasaran online. Bahkan diketahui sekitar hampir 70 persen UMKM yang berjalan dalam keanggotaan Rumah Pengusaha
Malang Raya (RPMR) belum mengenal pemasaran digital atau online, hanya ada 30 persen yang sudah memanfaatkan sistem pemasaran online(Sarwono, 2015). 2) Kesulitan dalam memperhitungkan omset, laba kotor sampai dengan laba bersih karena pembukuan yang masih manual seringkali menghambat bisnis UMKM untuk dapat berkembang(Saraswati, 2020). Walaupun sebenarnya terlihat pembukuan merupakan hal yang sepele, nyatanya dengan data 
pembukuanlah suatu perusahaan bisa mengukur keberhasilan dan merencanakan strategi perusahaan kedepannya

Selanjutnya kami mencoba memberikan solusi dari masalah tersebut melalui pembentukan workshop dan pendampingan. Proses workshop dan pendampingan ini bertujuan meningkatkan kualitas pemasaran serta tatakelola menejemen dan pembukuan, sehingga peserta harus berperan aktif melalui workshop ataupun pendampingan dalam pemasaran online dan tatakelola pembukuan usaha mereka. Dalam materi workshop ada beberapa hal sebagai berikut, a) pemasaran online dipakai sebagai sarana untuk memperkenalkan produk mereka yang diproduksi kepada konsumen, b). Mendeteksi keinginan pemakai. c). perencanaan pemasaran yang baik untuk UMKM. d). membangun branding. e). menciptakan komunikasi atau hubungan yang baik dengan konsumen. f). tatakelola manajemen pembukuan yang baik akan memberikan efek yang signifikan dalam perkembangan usaha UMKM.

\section{METODOLOGI PELAKSANAAN}

Aktivitas dalam kegiatan ini menggunakan metode workshop dan pendampingan yang mana dilakukan oleh UMKM sebagai user untuk menyelesaikan permasalahan pemasaran dengan kreatif dan inovatif dengan memanfaatkan aplikasi pemasaran digital. Workshop dan pendampingan yang dijalankan oleh pelaksana kami yaitu melalui workshop dan pendampingan RPMR kepada para anggotanya UMKM dengan memberikan workshop strategi pemasaran dan pendampingan dalam pemakaian dan pemanfaatan aplikasi pemasaran digital (ePasar)(Sarwono, 2015). Sasaran dari kegiatan ini adalah Anggota Rumah pengusaha Malang Raya (RPMR) sebanyak 450 UMKM di Kota dan Kabupaten Malang. Pengukuran untuk mengetahui tingkat keberhasilan para UMKM dengan memakai kuesioner, dan perubahan tiap-tiap
UMKM terhadap perkembangan kemajuan menggunakan statistic dan grafik.

Pemberian workshop dilaksanakan dalam waktu 2 hari dengan lama 180 menit pada setiap tatap mukanya. Sedangkan proses pendampingan para UMKM dilakukan dalam waktu 4 dengan 4 tahapan, yaitu pelaksanaan 1 tahap tiap minggu sebanyak 2 kali tatap muka. Kegiatan pendampingan ini bertujuan agar dapat meningkatkan tingkat keberhasilan sedangkan workshop bermanfaat untuk dapat membantu UMKM pada pemilihan strategi pemasaran yang sesuai. Oleh sebab itu, kedua aktivitas ini dilaksanakan agar dapat meningkatkan strategi pemasaran secara keseluruhan.

\section{HASIL DAN LUARAN}

Strategi yang digunakan dalam aktivitas ini, yaitu workshop pemilihan strategi pemasarang dengan aplikasi digital(Budianto, Dianawati, \& Iswahyudi, 2019). Workshop dipilih berdasarkan hasil pengkajian kepada 25 UMKM anggota dari RPMR yang mengalami kesulitan pemasaran didapatkan sebanyak $41 \%$ menggunakan peran tradisional atau dari pintu kepintu untuk mengatasi pemasaran produk. Penerapan teori pemasaran digital yang mana salah satunya adalah strategi pemasaran untuk pemberian kontribusi dalam mempertajam kreatifitas dan inovasi yang sudah ada agar dapat lebih meningkatkan hasil penjualan. 


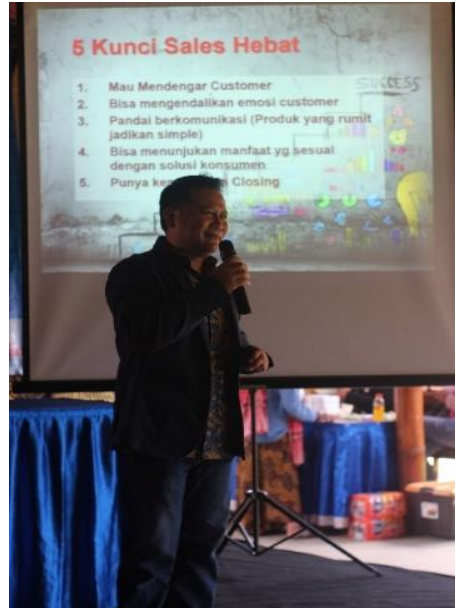

Gambar1. Pelaksanaan Workshop Strategi Pemasaran Digital

Pemilihan Workshop Strategi Pemasaran Digital untuk mengatasi pemasaran UMKM berdasarkan kreatifitas dan inovasi di era teknologi global agar menjadi efektif dan efisien. Workshop Strategi Pemasaran Digital bertujuan untuk membantu para angora RPMR dalam mengatasi masalah atau pemasaran dengan menekan biaya dan waktu yang akurat, tepat dan efisien (Saraswati, 2020). Workshop Strategi Pemasaran Digital berperan dalam bagi para UMKM agar mampu mengidentifikasi masalah pemasaran dengan teknologi aplikasi yang ada, mampu menggunakan aplikasi dalam pemasaran produk masing-masing UMKM, baik monitor dan hambatannya, serta mampu memaksimalkan penjualan lewat aplikasi dan dapat lebih mudah mengetahui hambatannya, serta dapat anlisa \& evaluasi hasil dari hambatan dalam penggunaannya .

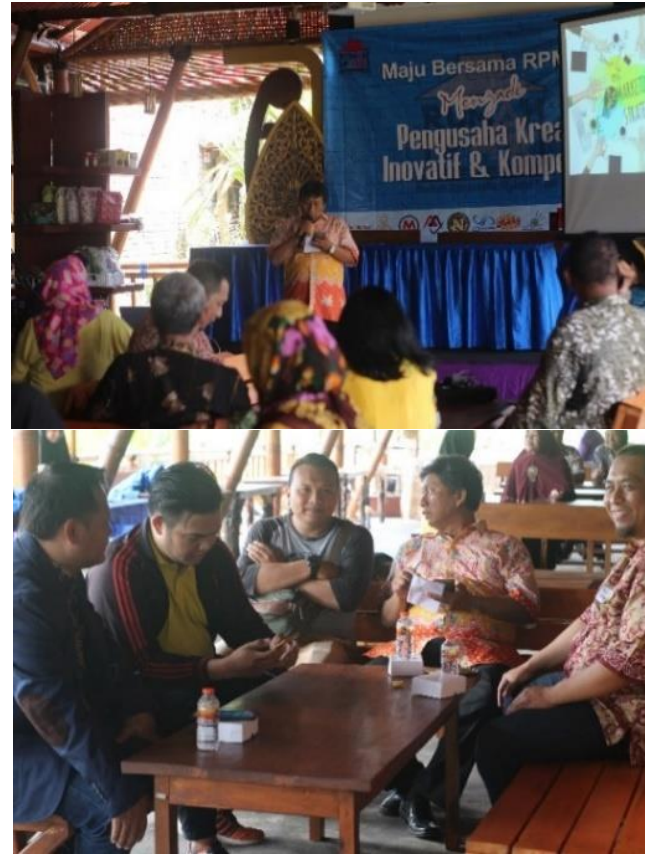

Gambar 2. Pelaksanaan Pembagian Kelompok UMKM

Hasil pemberian workshop dan pendampingan pada anggota RPMR yaitu para UMKM di Malang Raya menunjukkan adanya perubahan tingkat kepercayaan diri sehingga penjualan meningkat yang dialami UMKM Malang. Pengukuran tingkat percaya diri dan peningkatan penjualan digunakan saat sebelum dan setelah aktivitas workshop dan pendampingan. 

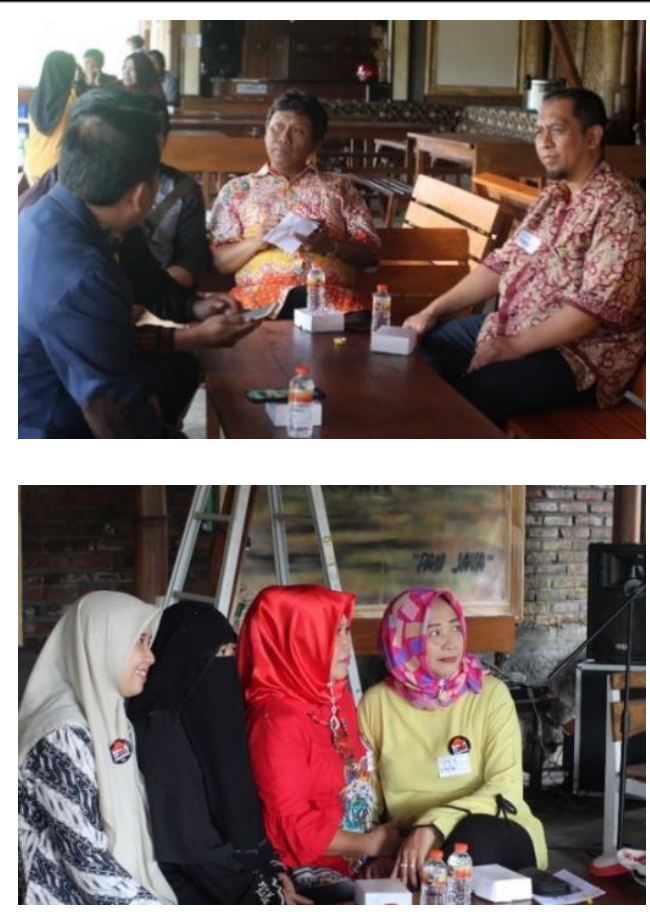

Gambar 3. Pelaksanaan Pendampingan

Diagram 1 menunjukkan tingkat penjualan dan percaya diri para UMKM mengalami perubahan setelah dilakukan implementasi dengan data sebagai berikut: UMKM yang tidak meningkat dari $0(0 \%)$ meningkat menjadi UMKM yang mengalami meningkat sedang 45 (10\%), UMKM menigkat baik 99 (22\%), UMKM yang meningkat cukup baik $113(25 \%)$ dan UMKM yang meningkat baik sekali 68 $(15 \%)$.

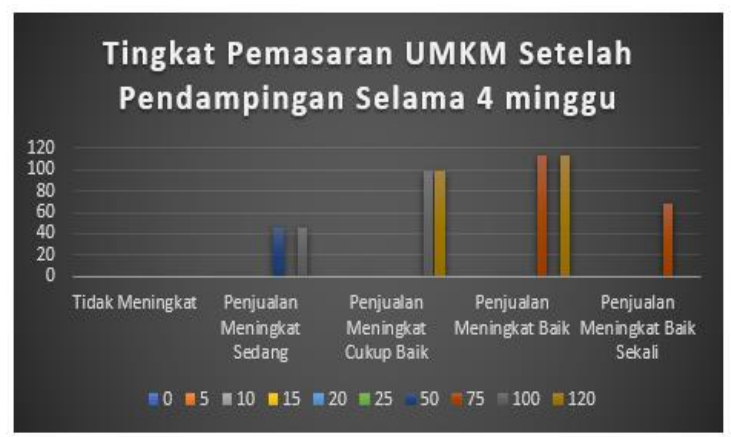

Diagram1. Distribusi frekuensi peningkatan penjualan dan percaya diri para UMKM di dalam anggota RPMR di Malang Jawa Timur

Workshop Strategi pemasaran digital dilakukan dalam waktu dua hari. Dalam tiap-tiap tatap muka selama 180 menit. Para UMKM diperbolehkan untuk sharing ilmu serta pomosi penjualan produknya dan pemakaian aplikasi. Namun para UMKM tidak diperbolehkan saling saling berbicang-bincang dengan UMKM yang lain. Konsentrasi dan fokus sangat berpengaruh secara positif pada konsentrasi para UMKM. Efek fokus secara teknis dapat meningkatkan atau menurunkan konsentrasi yang mana selanjutnya akan berpengaruh pada konsentrasi atau pemahaman. Workshop Strategi pemasaran digital ini memberikan motivasi serta harapan pada kemenangan bagi para UMKM sehingga berdampak atau keluhankeluhan yang disebabkan dari UMKM selama ini mendapatkan solusi. (Yuda, 2019)

Diagram 2 menunjukkan para UMKM mengalami perubahan kepercayaan diri selama pendampingan dan sesudah dilaksanakan implementasi menggunakan data sbb : UMKM dalam memakai kepercayaan dirinya meningkat menjadi 90 user $(20 \%)$. UMKM yang menggunakan cukup percaya diri 54 user (12\%), UMKM yang sedang berusaha percaya diri 9 user (2 $\%$ ), UMKM yang kurang percaya diri 1 user $(0,2 \%)$.

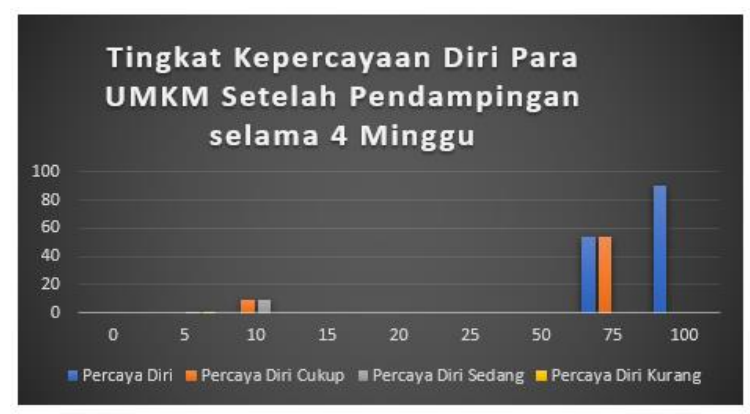

Diagram 2. Distribusi frekuensi

Kepercayaan Diri Para UMKM di dalam RPMR Malang Jawa Timur

Memanfaatkan Aplikasi e-Market menjadi strategi pemasaran untuk UMKM (Gunartin, 2017). Era teknologi digital seperti sekarang, arus komunikasi menjadi lebih cepat, lebih mudah, lebih murah dengan teknologi internet(Parrott, Roomi, \& Holliman, 2010). Kami hanya 
membutuhkan jaringan internet yang memadai dan dapat menjangkau konsumen yang lebih luas melalui sosmet. Disamping dapat mencapai target pasar yang lebih luas, lebih murah dan lebih efisien, selanjutnya strategi pemasaran untuk UMKM dan produk e-commerce yaitu dapat mempersingkat penyebaran penjualan produk, sehingga konsumen bisa mendapatkan penawaran lebih baik. (Zahir DM, 2019)

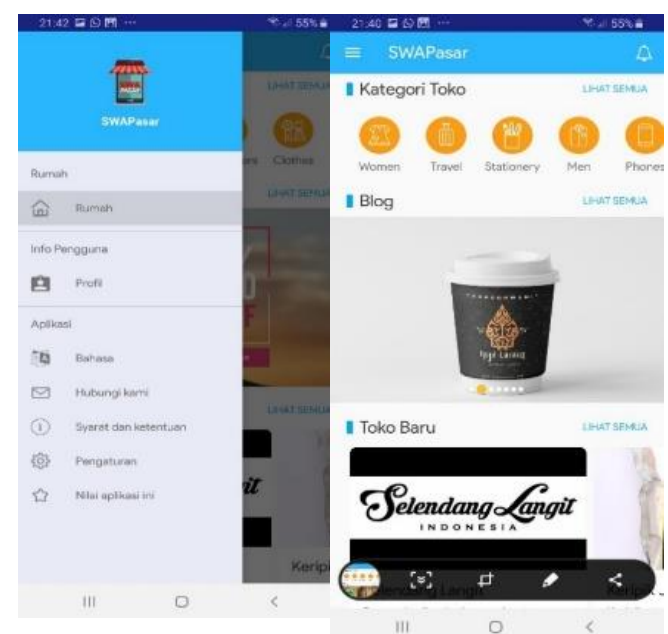

Gambar 4. Aplikasi

Pemasaran Digital untuk UMKM

Berdasarkan hasil pada diagram 2, terdapat empat jenis tipe kepercayaan diri dari para UMKM, yaitu, percaya diri, percaya diri cukup, percaya diri sedang dan percaya diri kurang. Dari ke empat tipe tersebut kami berusaha untuk merespon positif, dengan memberikan motivasi dan dan aplikasi pemasaran digital yang berfokus pada peningkatan pemasaran dan factor kepercayaan diri dan keyakinan dalam merespon kontribusi kami, sehingga membuat secara data dari kuesioner kami mandapatkan hasil yang baik atau positif. Dengan demikian maka, investasi dan kontribusi kami dalam memberikan aplikasi pemasaran digital dengan cara workshop dan pendampingan berhasil meningkatkan pemasaran dan kepercayaan diri yang signifikan dan positif.

\section{KESIMPULAN DAN SARAN}

Pemberian investasi pada Rumah Pengusaha Malang Raya (RPMR) Malang Jawa Timur ini, khususnya para UMKM sebagai anggotanya dengan cara kelompok dengan memberikan workshop serta pendampingan dengan hasil positif. Investasi Aplikasi Pemasaran Digital dengan kegiatan ini memberikan dampak yang sangat signifikan dalam meningkatkan penjualan atau pemasaran produk UMKM dan menimbulkan keyakinan baru, sehingga membuat para UMKM menjadi lebih percaya diri dan makin berfikir positif. Selain itu Investasi Aplikasi ini akan terus disesuaikan dengan perkembangan teknologi dan kebutuhan para UMKM untuk menjadikannya lebih kreatif dan inovasi, serta berfikir selalu positif.

\section{UCAPAN TERIMAKASIH}

Ucapan terimakasih kepada Universitas Kanjuruhan Malang, sebagai Lembaga yang telah mewadahi kami, selanjutnya kepada Rumah Pengusaha Malang Raya (RPMR) yang mensupport langsung kepada para UMKM Malang raya dan kepada DIKTI selalu pendukung dana pengabdian ini.

\section{DAFTAR PUSTAKA}

Budianto, A. E., Dianawati, E., \& Iswahyudi, D. (2019). Penerapan Program Pengembangan Kewirausahaan Pada Mahasiswa (Tenant) di Universitas Kanjuruhan Malang. Kumawula: Jurnal Pengabdian Kepada Masyarakat, 2(1), 93. https://doi.org/10.24198/kumawula.v $2 \mathrm{i} 1.23475$

Gunartin. (2017). Penguatan Umkm Sebagai Pilar Membangun Ekonomi 
Bangsa. Jurnal Pendidikan, Hukum, Dan Bisnis, 2(2), 1-10.

Parrott, G., Roomi, M. A., \& Holliman, D. (2010). An analysis of marketing programmes adopted by regional small and medium-sized enterprises. Journal of Small Business and Enterprise Development, 17(2), 184203.

https://doi.org/10.1108/14626001011 041201

Saraswati, E. (2020). Strategi Perencanaan dan Biaya Pemasaran yang Efektif bagi UMKM Mitra Binaan PT. Semen Indonesia Tbk. Journal of Dedicators Community, 3(3), 97-105. https://doi.org/10.34001/jdc.v3i3.104 0

Sarwono, H. A. (2015). Profil Bisnis Usaha Mikro, Kecil Dan Menengah (Umkm). Bank Indonesia Dan LPPI, 1-135. 